\title{
A PARTICIPAÇÃO DAS MICROEMPRESAS E EMPRESAS DE PEQUENO PORTE NAS CONTRATAÇÕES PÚBLICAS DO GOVERNO FEDERAL
}

\author{
PARTICIPATION OF MICRO AND SMALL COMPANIES IN PUBLIC \\ CONTRACTS OF THE FEDERAL GOVERNMENT
}

\author{
Recebido: 18/12/2018 - Aprovado: 2/12/2019 - Publicado:02/01/2020 \\ Processo de Avaliação: Double Blind Review
}

\author{
Carlos Alberto de França \\ https://orcid.org/0000-0003-4020-9207 \\ UNIFACCAMP \\ carlosfranca.re@hotmail.com \\ Fernando Augusto Moutinho Junior \\ https://orcid.org/0000-0002-3778-4000 \\ UNIFACCAMP \\ fernandoamj1@gmail.com
}

RESUMO: Objetivo deste artigo é analisar a participação das microempresas e empresas de pequeno porte nas contratações públicas do Governo Federal, com base nos dados do Painel de Compras, uma nova ferramenta lançada em 2015, voltada para remodelar a atuação do Sistema de Serviços Gerais (SISG) do governo federal. Os resultados indicam que as contratações públicas do governo federal movimentaram mais $\mathrm{R} \$ 258$ bilhões de reais entre 2012 e 2016 com 50,85\% de participação das ME/EPP e desse percentual $22,72 \%$ das compras foram homologadas para ME/EPP, sendo que, a partir de 2014 esse percentual de compras homologadas para ME/EPP diminui significativamente para 13,31 \% em 2016. A principal conclusão deste trabalho é a necessidade de atualizações e/ou alterações nas normas e legislações como a Lei Complementar $n^{\circ}$ 123/2006, Lei Complementar $n^{\circ} 147 / 2014$, Lei $n^{\circ} 8.666 / 93$ e Decreto $n^{\circ} 8.538 / 2015$ para aumentar e melhorar a participação de microempresas e empresas de pequeno porte nas compras do Governo Federal e consequentemente nos Estados, Distrito Federal e Municípios.

Palavras-Chave: microempresas e pequenas empresas, painel de compras, contratações públicas, Governo Federal. 
ABSTRACT: The objective of this article is to analyze the participation of micro and small enterprises in the public contracting of the Federal Government, based on data from the Procurement Panel, a new tool launched in 2015, aimed at reshaping the performance of the General Service System SISG) of the federal government. The results indicate that public contracting by the federal government increased $R \$ 258$ billion between 2012 and 2016, with a 50.85\% share of ME / EPP and 22.72\% of purchases were homologated for ME / EPP. that from 2014 this percentage of purchases approved for ME / EPP decreases significantly to $13.31 \%$ in 2016. The main conclusion of this work is the need for updates and / or changes in standards and legislation such as Complementary Law 123 /2006, Complementary Law No. 147/2014, Law No. 8.666/93 and Decree No. 8,538/2015 to increase and improve the participation of micro and small companies in the purchases of the Federal Government and consequently in the States, Federal District and Municipalities.

Keywords: microenterprises and small companies, purchasing panel, public contracting, Federal Government.

\section{INTRODUÇÃO}

O governo federal é o maior consumidor do país, segundo dados do Painel de Compras do Ministério do Planejamento, entre os anos de 2012 a 2016, as compras do governo federal somaram mais de R \$ 258 bilhões de reais. Porém, somente 50,85\% tiveram a participação de Micro e Pequenas Empresas - ME/EPP e, desse percentual, apenas $22,72 \%$ das compras foram homologadas para ME/EPP, sendo que, a partir de 2014, esse percentual de compras homologadas para ME/EPP diminuiu significativamente para $13,31 \%$ em 2016. São as principais geradoras de riqueza do comércio no Brasil, já que respondem por $53,4 \%$ do PIB deste setor.

No PIB da indústria, a participação das micro e pequenas $(22,5 \%)$ já se aproxima das médias empresas $(24,5 \%)$. No setor de serviços, mais de um terço da produção nacional $(36,3 \%)$ tem origem nos pequenos negócios e, as MPE representavam 44\% dos empregos formais em serviços e aproximadamente $70 \%$ dos empregos gerados no comércio (SEBRAE, 2014). 
Segundo o relatório executivo do SEBRAE (fevereiro/2015), as MPEs geraram, em 2011, 27\% do valor adicionado do conjunto de atividades pesquisadas (PIB), tendo sido observado uma elevação desse percentual quando comparado aos anos anteriores, quando representava $21 \%$ em 1985 e, 23,2\% em 2001.

O segmento das MPEs responde por $99,2 \%$ de todos os empreendimentos brasileiros, sendo responsável pela geração da maioria dos postos de trabalho formais e pela totalidade dos informais (SEBRAE, 2005).

A Lei $n^{\circ} 7.256 / 84$ e a Lei ${ }^{\circ}$ 9.841/99, unificaram vários assuntos de interesse das micro e pequenas empresas, porém, o mesmo não dispunha em seu escopo disposições sobre contratos governamentais (BRASIL, 2017). O tratamento diferenciado para micro e pequenas empresas está disposto na Constituição Federal de 1988; Emenda Constitucional $n^{\circ} 42$, de 19.12.2003, o qual produziu efeitos a partir de 2006, com a publicação da Lei $n^{\circ}$ 123/2006, foi estabelecido a obrigatoriedade do tratamento diferenciado e favorecido para as microempresas e empresas de pequeno porte nas contratações públicas.

O efeito inovador da legislação implicou em mudanças culturais nos órgãos púbicos, novos procedimentos gerando relevantes melhorias na participação e na taxa de eficácia no resultado final dos certames licitatórios para as micro e pequenas empresas. A publicação da Lei Complementar no. 123/06, possibilitou e facilitou o acesso aos mercados das micro e pequenas empresas, no tocante às participações nos procedimentos licitatórios instaurados pela Administração Pública.

Para o desenvolvimento econômico e social das MPEs, a Lei Complementar n. 123, de 14 de dezembro de 2006, alterada pela Lei Complementar $n^{\circ} 147$, de 07 de agosto de 2014, instituíram o tratamento diferenciado das micro e pequenas empresas (ME) e empresas de pequeno porte (EPP) nos certames licitatórios. Portanto, o governo federal tem como estratégia para apoiar o crescimento econômico o uso do seu poder de compras para alavancar o desenvolvimento de micro e pequenas empresas (BRASIL, 2014). Após essas ações governamentais, a participação das ME/EPP nas compras públicas do governo federal aumentou, chegando a mais de R\$ 51 bilhões em 2016.

Verifica-se que o governo federal vem realizando esforços para diminuir as diferenças entre as grandes empresas e pequenas empresas, com o objetivo de assegurar às ME/EPP igualdade de oportunidades e incentivos para as disputas nas compras 
públicas da União. Os estados e municípios dentro desse escopo também têm incentivado os micros empresários a participarem das licitações públicas facilitando o acesso, através de facilitação de cadastramento, manuais, treinamentos e cursos.

O objetivo deste estudo foi analisar a participação de microempresas e empresas de pequeno porte nos processos de compras do governo federal no período de 2012 a 2016, e identificar os critérios de ordem de preferência dos pagamentos aos fornecedores de bens e serviços do governo federal.

O método utilizado apresenta toda a legislação pertinente ao tema e na demonstração dos valores licitados pelo governo federal, comparando a participação das micro e pequenas empresas nos processos de compras do governo federal em dois cenários. O primeiro cenário é do ano de 2015 ao ano 2016 e, o segundo cenário, os últimos cinco anos que englobam o período do ano de 2012 ao ano de 2016, utilizando como coleta de dados o sistema do Painel de Compras desenvolvido pelo Ministério do Planejamento, Desenvolvimento e Gestão.

Os resultados demonstraram que tratamento favorecido, diferenciado e simplificado para as MPEs nas contratações públicas ainda têm pouco efeito, havendo um amplo mercado a ser explorado pelas pequenas empresas nas contratações do governo federal.

Ao final do estudo, ficam as propostas para atualizações e/ou alterações nas normas e legislações para aumentar e melhorar a participação de microempresas e empresas de pequeno porte nas compras governamentais, sem, no entanto, esquecer-se do comprometimento com a qualidade, ganhando em diferencial de competitividade e melhorando ainda mais o seu posicionamento no mercado perante à concorrência, aumentando e melhorando a participação de microempresas e empresas de pequeno porte nas compras do governo federal e consequentemente nos estados, Distrito Federal e municípios. 


\section{LICITAÇÕES PÚBLICAS - CONCEITOS E FINALIDADES}

Para Marçal Justen Filho, “A definição do tipo de licitação produz reflexos não apenas sobre o julgamento das propostas. O próprio procedimento licitatório, em toda sua fase externa, variará consoante o tipo de licitação" (JUSTEN FILHO, 2008).

A licitação é ramificada do direito público brasileiro, remontando ao século XIX, através do Decreto n $^{\circ} 2.926$ de 14 de maio de 1862, cujos termos regulava as arrematações e serviços a cargo do Ministério da Agricultura, Comércio e Obras Públicas. Em 30 de dezembro de 1909, foi aprovada a Lei Orçamentária $n^{0} 2.221$, que fixou regras a serem observadas nos processos das concorrências e, a partir de então, surgindo novas leis regulamentadoras, tais como: Lei 3.323/1917; Lei 3991/1920; Lei 3.454/1981; Decreto 4.555/1922 e o Código de Contabilidade Pública e o seu Regulamento aprovado pelo Decreto 15.783/1922, ficando em vigor por 50 anos, até que surgiu o Decreto-Lei $\mathrm{n}^{\circ} 200$ de 27 de Janeiro de 1967, tratando de forma mais detalhada as Licitações e os Contratos Administrativos.

A exigência do processo licitatório encontra guarida no art. 37, XXI, da CF/88, que estabelece a obrigatoriedade no conclave para as obras, serviços, compras e alienações, ressalvadas as excepcionalidades previstas em lei. Visando regulamentar esse inciso, foi editada a Lei $n^{\circ} 8.666 / 93$, alterada pelas Leis $n^{\circ} 8.883 / 94$ e alterações. A Lei $n^{\circ} 8.666 / 93$, estabelece as normas gerais sobre licitações e contratos. Nesses termos, estados-membros, Distrito Federal e municípios poderão ter suas leis específicas de licitação, desde que não conflitem com as normas gerais estatuídas pela União.

Segundo Di Pietro (2008), a licitação é um procedimento administrativo, instaurado pela própria Administração Pública, constituída pela prática ordenada e sucessiva de uma série de atos, tendo cada um autonomia e finalidade.

\subsection{Modalidades de licitações}

São cinco modalidades de licitação: concorrência, tomada de preço, convite, concurso e leilão (art. 22, Lei $\mathrm{n}^{\mathrm{o}}$ 8.666/93). Foi inserida uma nova modalidade por intermédio da Medida Provisória n $n^{\circ}$ 2.026/2000, e convertida na Lei $n^{\circ} 10.520 / 2002$, a modalidade licitatória de pregão, hoje temos seis modalidades de licitação:

Concorrência - É a modalidade de licitação entre quaisquer interessados que, na fase inicial de habilitação preliminar, comprovem possuir os requisitos mínimos de 
qualificação exigidos no edital para a execução de seu objeto (art. $22, \S 1^{\circ}$ ).

Essa modalidade deve ser utilizada para contratações de maior valor (art. 23, inciso I, alínea “c”) ou que as especificações e/ou a complexidade do objeto necessitem de maior prazo, o prazo mínimo para ao recebimento das propostas ou da realização do evento será de quarenta e cinco dias (art. 21, § 2, inciso I, alínea “b”) e de trinta dias (art. $21, \S 2^{\circ}$, inciso II, alínea “a”).

Tomada de Preços - É a modalidade de licitação de vulto intermediário entre interessados devidamente cadastrados ou que atenderem a todas as condições exigidas para cadastramento até o terceiro dia anterior à data do recebimento das propostas, observada a necessária qualificação. (art. $22, \S 2^{\circ}$ ).

Nessa modalidade, também podem participar os interessados que atenderem a todas as condições exigidas parta cadastramento até o terceiro dia anterior à data do recebimento das propostas, o prazo mínimo para ao recebimento das propostas ou da realização do evento será de trinta dias (art. $21, \S 2^{\circ}$, inciso II, alínea “b”) e de quinze dias (art. $21, \S 2^{\circ}$, inciso III).

Convite - É a modalidade de licitação entre interessados do ramo pertinente ao seu objeto, cadastrados ou não, escolhidos e convidados em número mínimo de 3 (três) pela unidade administrativa, a qual afixará, em local apropriado, cópia do instrumento convocatório e o estenderá aos demais cadastrados na correspondente especialidade que manifestarem seu interesse com antecedência de até 24 (vinte e quatro) horas da apresentação das propostas. (art. $22, \S 3^{\circ}$ ), o prazo mínimo para ao recebimento das propostas ou da realização do evento será de cinco dias (art. $21, \S 2^{\circ}$, inciso IV).

Concurso - É a modalidade de licitação entre quaisquer interessados para escolha de trabalho técnico, científico ou artístico, mediante a instituição de prêmios ou remuneração aos vencedores, conforme critérios constantes de edital (art. 22, $\S 4^{\circ}$ ) e o prazo mínimo para ao recebimento das propostas ou da realização do evento será de quarenta e cinco dias (art. 21, $2^{\circ}$, inciso I, alínea “a”).

O concurso se exaure com a classificação dos trabalhos e a entrega do prêmio ou pagamento da remuneração, não conferindo qualquer direito a contrato com a Administração.

Leilão - É a modalidade de licitação entre quaisquer interessados para a venda de bens móveis inservíveis para a Administração ou de produtos legalmente apreendidos ou 
penhorados, ou para a alienação de bens imóveis prevista no art. 19, a quem oferecer o maior lance, igual ou superior ao valor da avaliação (art $22, \S 5^{\circ}$ ), o prazo mínimo para ao recebimento das propostas ou da realização do evento será de quinze dias (art. $21, \S$ $2^{\circ}$, inciso III).

Inexibilidade e Dispensa de Licitação - Apesar do ordenamento jurídico brasileiro ter referendado a licitação como regra para a contratação, por parte da Administração Pública, esse prevê exceções nas quais a contratação pode ser realizada de forma direta. As previsões transcritas tanto no art. 17 quanto no art. 24 da Lei 8.666/93, só devem ocorrer por razões de interesse público e nos casos expressamente previstos.

Uma das formas de contratação direta é a inexibilidade de licitação, que tem como característica o fato de que a licitação não é possível, haja vista que um dos possíveis competidores possui qualidades que atendem de forma exclusiva às necessidades da administração pública, inviabilizando os demais participantes.

A utilização desse dispositivo deverá obedecer a comprovação de exclusividade em relação à especificação do item a ser contratado, sendo vedada a indicação de uma marca específica quando houver mais de uma que atenda as exigências descritas no item.

Outra forma de contratação direta é através da dispensa de licitação, que tem como característica o fato de que a licitação é possível, entretanto não se realiza por conveniência administrativa. Para caracterizar a dispensa, a Lei 8.666/93, no seu art. 24, enumerou 24 situações que tornam facultativo o processo licitatório. Fatores como emergência e a relação custo-benefício, são exemplos do que deve ser levado em consideração na opção deste tipo de contratação.

Pregão - É uma modalidade de licitação juntamente com as demais citadas anteriormente. É a modalidade para aquisição de bens e serviços comuns. (art. $1^{\circ}$, Lei ${ }^{\circ}$ 10.520/02). Consideram-se bens e serviços comuns, para os fins e efeitos deste artigo, aqueles cujos padrões de desempenho e qualidade possam ser objetivamente definidos pelo edital, por meio de especificações usuais no mercado. (art. $1^{\circ}$, Parágrafo único, Lei $\mathrm{n}^{\mathrm{o}} 10.520 / 02$ ), o prazo mínimo para ao recebimento das propostas ou da realização do evento será de oito dias (art. $4^{\circ}$, inciso V, da Lei $\left.n^{\circ} 10.520 / / 02\right)$.

A modalidade Pregão é uma modalidade de licitação de tipo menor preço, destinada à seleção da proposta mais vantajosa de contratação de bem ou serviço comum, caracterizada pela existência de uma fase competitiva inicial, em que os licitantes 
dispõem do ônus de formular propostas sucessivas, e de uma fase posterior de verificação dos requisitos de habilitação e de satisfatoriedade das ofertas (JUSTEN FILHO, 2009, p.9).

No pregão existem duas formas: o pregão presencial e o pregão eletrônico, sendo que esse deve ser realizado preferencialmente. O pregão presencial caracteriza-se pela presença física dos fornecedores interessados no certame na localidade do órgão público. O pregão eletrônico se produz com a utilização de uma rede de computadores, a exemplo da internet.

Sampaio (2012) considera o pregão eletrônico importante para as compras públicas, aliada à relevância das micro e pequenas empresas para o desenvolvimento econômico e social do país bem como para a geração de emprego e renda.

Poderá também, ser aplicada no que couber, a Lei n ${ }^{\circ} 8.666$, de 21/06/93, que trata das licitações e contratos, na forma prevista no art. $9^{\circ}$ da Lei 10.520/2002, aplicando-se subsidiariamente, para a modalidade de pregão, as normas da lei $\mathrm{n}^{\circ} 8.666$, de 21 de junho de 1993.

\subsection{Painel de compras do governo federal}

O Painel de Compras do Governo Federal é uma ferramenta que apresenta em um só local os principais números das contratações públicas e, tem por finalidade oferecer um panorama dos gastos públicos e do comportamento licitatório no âmbito da Administração Pública Federal. Foi desenvolvido de forma a conter informações de todos os órgãos que compõem o Sistema Integrado de Serviços Gerais - SISG (BRASIL, 2015).

Em 1994, o Decreto n ${ }^{\circ} 1.094$ regulamentou os arts. 30 e 31 do Decreto-Lei n ${ }^{\circ} 200$, de 25 de fevereiro de 1967, e instituiu o SISG. Esse sistema já havia sido objeto do revogado Decreto no 75.657 , de 24 de abril de 1975.

O SISG surge, assim, como parte integrante de um sistema administrativo orgânico que engloba toda a Administração Pública Federal, num esforço de coordenação das atividades de logística pública com vistas a maior eficiência. Trata-se de um entre os vários sistemas de atividades auxiliares da administração, responsáveis pela execução de atividades de cunho transversal (BRASIL, 2015).

O COMPRASNET - Portal de Compras do Governo Federal é um site web instituído

REMIPE- Revista de Micro e Pequenas Empresas e Empreendedorismo da Fatec Osasco 
pelo Ministério do Planejamento, Orçamento e Gestão - MP, para disponibilizar à sociedade informações referentes às licitações e contratações promovidas pelo governo federal, bem como permitir a realização de processos eletrônicos de aquisição.

O painel de compras é uma plataforma que extrai os dados das compras do governo federal alimentados pelos diversos órgãos. Foi desenvolvido pela Secretaria de Logística e Tecnologia da Informação (SLTI) do Ministério do Planejamento, Orçamento e Gestão (MPOG) e apresentada no ano de 2015, como uma nova ferramenta voltada para remodelar a atuação do Sistema de Serviços Gerais (SISG), composto por 367 órgãos (BRASIL, 2015).

A ferramenta foi desenvolvida para melhorar a transparência e a eficiência do processo de compras governamentais e reúne informações nas áreas de licitação, contratos e atas de registro de preço. Assim, os gestores públicos podem visualizar melhor o desempenho das aquisições realizadas e dos riscos envolvidos (BRASIL, 2015).

O painel de compras disponibiliza informações sobre dados de licitações, contratos, atas de registro de preços e preços praticados, destina-se também a ser uma importante ferramenta na transparência governamental, permitindo a todo cidadão a criação de indicadores e consultas personalizadas, bem como exportar os dados em diversos formatos (BRASIL, 2015).

Essa ferramenta pretende aprimorar o processo de compras dos órgãos públicos federais, ao possibilitar a identificação das melhores práticas na área e seu desenvolvimento faz parte de uma série de ações e melhorias na disponibilidade de informações dos sistemas estruturantes que são mantidos pelo Ministério do Planejamento. Tais iniciativas visam ampliar o acesso à informação e, consequentemente, melhorar a governança pública. Também, fazem parte do compromisso da Secretaria de Gestão - SEGES, com a prestação de serviços públicos de qualidade (BRASIL, 2015).

\section{MICROEMPRESAS E EMPRESAS DE PEQUENO PORTE}

São consideradas microempresas ou empresas de pequeno porte, conforme o Art. $3^{\circ}$ da Lei Complementar n.123/2006: 
I - no caso da microempresa, aufira, em cada ano-calendário, receita bruta igual ou inferior a $\mathrm{R} \$ 360.000,00$ (trezentos e sessenta mil reais); e

II - no caso de empresa de pequeno porte, aufira, em cada ano-calendário, receita bruta superior a $\mathrm{R} \$ 360.000,00$ (trezentos e sessenta mil reais) e igual ou inferior a $\mathrm{R} \$ 4.800 .000,00$ (quatro milhões e oitocentos mil reais). (Redação dada pela Lei Complementar $n^{\circ} 155$, de 2016)

A evolução histórica da legislação das micro e pequenas empresas teve seu início no país a partir das Leis $\mathrm{n}^{\circ} 7.256 / 84, \mathrm{n}^{\circ}$ 9.841/99, unificaram vários assuntos de interesse das micro e pequenas empresas, porém, o mesmo não dispunha em seu escopo disposições sobre contratos governamentais. A Lei n. 9.841/99 estabeleceu em seu art. 24 "a política de compras governamentais dará prioridade à microempresa e à empresa de pequeno porte, individualmente ou de forma associada, com processo especial e simplificado nos termos da regulamentação desta Lei” (BRASIL, 2017).

Em 2003, foi editada a Emenda Constitucional n 42, no art. 146, da Constituição Federal, que instituiu a criação de uma Lei Complementar para regulamentar um regime único de arrecadação de impostos e contribuições da União, estados, Distrito Federal e municípios, que justificou o Projeto de $\mathrm{LC} \mathrm{n}^{\circ}$ 123/2004, dando origem à $\mathrm{LC}^{\circ} 123$ de 14 de dezembro de 2006.

O Estatuto das Micro e Pequenas Empresas surgiu da iniciativa do SEBRAE e de empresários interessados em consolidar um projeto, que realmente conseguisse suprir a real necessidade das ME e EPP, projetos esses que se agregavam e foram substituídos pelo novo texto consolidado em 2005, incluindo a novidade dos dispositivos sobre acesso aos mercados governamentais.

O tratamento diferenciado para a micro e pequena empresa está disposto na Constituição Federal de 1988; Emenda Constitucional no 42, de 19.12.2003:

\footnotetext{
Art. 146. Cabe à lei complementar: III - estabelecer normas gerais em matéria de legislação tributária, especialmente sobre:

d) definição de tratamento diferenciado e favorecido para as microempresas e para as empresas de pequeno porte, inclusive regimes especiais ou simplificados no caso do imposto previsto no art. 155, II, das contribuições previstas no art. 195, I e $\S \S 12$ e 13, e da contribuição a que se refere o art. 239."

Emenda Constitucional no 6, de 1995):
} 
Art. 170. A ordem econômica, fundada na valorização do trabalho humano e na livre iniciativa, tem por fim assegurar a todos existência digna, conforme os ditames da justiça social, observados os seguintes princípios:

IX - tratamento favorecido para as empresas de pequeno porte constituídas sob as leis brasileiras e que tenham sua sede e administração no País." \{grifo do autor\}

Art. 179. A União, os Estados, o Distrito Federal e os Municípios dispensarão às microempresas e às empresas de pequeno porte, assim definidas em lei, tratamento jurídico diferenciado, visando a incentivá-las pela simplificação de suas obrigações administrativas, tributárias, previdenciárias e creditícias, ou pela eliminação ou redução destas por meio de lei (grifo do autor).

A Lei Complementar $n^{\circ} 123$, de 14 de dezembro de 2006, estabeleceu normas gerais relativas ao tratamento diferenciado e favorecido a ser dispensado às microempresas e empresas de pequeno porte no âmbito dos Poderes da União, dos estados, do Distrito Federal e dos municípios.

De acordo com o Art. 47, estabelece:

Nas contratações públicas da administração direta e indireta, autárquica e fundacional, federal, estadual e municipal, deverá ser concedido tratamento diferenciado e simplificado para as microempresas e empresas de pequeno porte objetivando a promoção do desenvolvimento econômico e social no âmbito municipal e regional, a ampliação da eficiência das políticas públicas e o incentivo à inovação tecnológica.

Dentre os aspectos formais e de regulação da administração pública e suas tentativas de melhorar o ambiente legal para as MPEs, podemos destacar: procedimentos licitatórios especiais e a participação em licitações públicas, o estímulo ao crédito e à capitalização, conforme previstos na Lei Geral das MPEs (SEBRAE, 2014).

O capítulo V da Lei $n^{\circ}$ 123/06, dispõe sobre os procedimentos licitatórios especiais e a participação em licitações públicas de forma a promover o desenvolvimento econômico e social das MPEs, a administração pública poderá realizar processo licitatório:

I - destinado exclusivamente à participação de MPE nas contratações de até $\mathrm{R} \$ 80 \mathrm{mil}$;

II - poderá, em relação aos processos licitatórios destinados à aquisição de obras e serviços, exigir dos licitantes a subcontratação de microempresa ou empresa de pequeno porte; 
III - deverá estabelecer, em certames para aquisição de bens de natureza divisível, cota de até $25 \%$ (vinte e cinco por cento) do objeto para a contratação de microempresas e empresas de pequeno porte;

IV - comprovação de regularidade fiscal das MPEs somente será exigida para efeito de assinatura do contrato. Havendo alguma restrição na comprovação da regularidade fiscal, a MPE terá dois dias úteis, prorrogáveis por igual período a critério da administração pública, para regularização;

$\mathrm{V}$ - não houver um mínimo de 3 (três) fornecedores competitivos enquadrados como microempresas ou empresas de pequeno porte sediados local ou regionalmente e capazes de cumprir as exigências estabelecidas no instrumento convocatório;

VI - o tratamento diferenciado e simplificado para as microempresas e empresas de pequeno porte não for vantajoso para a administração pública ou representar prejuízo ao conjunto ou complexo do objeto a ser contratado;

VII - a licitação for dispensável ou inexigível, nos termos dos arts. 24 e 25 da Lei $\mathrm{n}^{\circ}$ 8.666, de 21 de junho de 1993, excetuando-se as dispensas tratadas pelos incisos I e II do art. 24 da mesma Lei, nas quais a compra deverá ser feita preferencialmente de microempresas e empresas de pequeno porte, aplicando-se o disposto no inciso I do art. 48.

VIII - permite que a Administração Pública priorize a contratação de MPE locais ou regionais com diferenças justificadas de até $10 \%$ a mais.

IX - permite que a Administração Pública priorize a contratação de MPE locais ou regionais com diferenças justificadas de até $10 \%$ a mais.

O Capítulo IX da Lei Geral estabelece uma série de ações de estímulo ao crédito

e à capitalização:

I - o Poder Executivo proporá, sempre que necessário, medidas que estimulem o acesso ao crédito pelas MPEs;

II - os bancos terão que desburocratizar o processo de concessão de crédito para MPE (que faturam efetivamente até R \$ 3,6 milhões), bem como justificar pormenorizadamente a não utilização dos recursos previstos em seus orçamentos;

III - os bancos públicos e privados não poderão contabilizar, para cumprimento de metas, empréstimos realizados a pessoas físicas, ainda que sócios de empresas, como disponibilização de crédito para MPE;

IV - os fundos garantidores de risco de crédito empresarial que possuam participação da União na composição do seu capital atenderão, sempre que possível, as operações de crédito que envolvam microempresas e empresas de pequeno porte, definidas na forma do art. 3 - desta Lei;

$\mathrm{V}$ - fundos garantidores de crédito com participação da União deverão dar tratamento diferenciado às MPE, sempre que possível;

VI - a obrigatoriedade do Banco Central em divulgar as operações de crédito vai provocar uma competição de resultados entre as instituições na concessão de crédito para MPE;

VII - recursos financeiros do Fundo de Amparo ao Trabalhador (FAT) serão destinados para cooperativas de crédito de empreendedores de MPEs. 
O IBGE (2003), nesse mesmo sentido, destaca algumas características predominantes e fragilidades do segmento de micro e pequenas empresas: baixa intensidade de capital; altas taxas de natalidade e de mortalidade; forte presença de proprietários, sócios e membros da família como mão de obra ocupada nos negócios; poder decisório centralizado e estreito vínculo entre os proprietários e as empresas, não se distinguindo em termos contábeis e financeiros as pessoas física e jurídica; registros contábeis são pouco adequados; baixa qualificação da mão de obra utilizada; baixo investimento em inovação tecnológica; e relação de complementaridade e subordinação com as empresas de grande porte. Problemas esses que poderiam ser resolvidos com a capacitação do empresário para o gerenciamento. Uma gestão eficiente é ponto fundamental para o aumento de competitividade e a eficiência de uma empresa, trata-se exatamente de relação direta entre gestão e vantagens competitiva.

As mudanças promovidas pela Lei $\mathrm{n}^{\circ} 123 / 2006$, até o momento não há clareza quanto à posição atual das MPE nas compras públicas brasileiras (CABRAL; REIS; SAMPAIO, 2015).

\section{MÉTODOS}

Para alcançar os objetivos propostos, bem como obter as informações necessárias para a realização da pesquisa, utilizou-se a pesquisa do tipo exploratória em um procedimento quantitativo.

Segundo Gil (1999), a pesquisa exploratória tem como objetivo principal desenvolver, esclarecer e modificar conceitos e ideias, tendo em vista a formulação de problemas mais precisos ou hipóteses pesquisáveis para estudos posteriores.

Para coletar os dados, utilizou-se como método uma pesquisa documental em fontes secundárias. Segundo Minayo (2009), são provenientes daquelas informações de caráter objetivo, passíveis de serem encontrados em documentos oficiais e/ou outras fontes (censos, relatórios, registros).

Dessa forma, são considerados como objeto deste estudo as contratações públicas no âmbito do governo federal; as evidências do estudo provêm de análises às normas e legislações vigentes e dos processos de compras do governo federal, dos anos de 2012 a 
2016, através dos dados e informações do Painel de Compras do Ministério do Planejamento, Desenvolvimento e Gestão, para que fossem obtidos os quantitativos e valores da participação das MPEs, com análise temporal e de valores.

Para atingir o objetivo da pesquisa, a coleta dos dados iniciou-se, primeiramente, com uma busca no Portal Brasileiro de Dados Aberto do Ministério do Planejamento, Desenvolvimento e Gestão, a fim de verificar o quantitativo de fornecedores cadastrados na base de dados do governo federal por porte. Na sequência, verificaram-se os números de processos de compras do ano de 2012 a 2016, analisando a evolução no respectivo período. Os dados foram coletados em 2018 e, atualizados até 31 de dezembro de 2016, utilizando os anos completos para efeito de comparação.

Na sequência, com os dados coletados, realizou-se uma análise do cenário de 2015 e 2016, identificando: as quantidades de processos de compras; valores contratados pelo governo federal para as MPEs e das empresas de outros portes, sendo o mesmo critério utilizado para analisar o cenário de 2012 a 2016.

Por fim, para análise de dados, empregou-se estatística descritiva para levantamento de médias e frequências para posterior elaboração de tabelas e gráficos.

\section{RESULTADOS E DISCUSSÃO}

Os resultados apresentados analisam a participação das micro e pequenas empresas nos processos de compras do governo federal em dois cenários. O primeiro cenário é do ano de 2015 ao ano 2016, e o segundo cenário, os últimos cinco anos que englobam o período do ano de 2012 ao ano de 2016, utilizando como coleta de dados o sistema do Painel de Compras desenvolvido pelo Ministério do Planejamento, Desenvolvimento e Gestão.

Como podemos observar no Gráfico 1, a quantidade de MPE's representa 72,97\% e, das empresas de outros portes essa representatividade é de $27,03 \%$ do total de fornecedores cadastrados na base de dados do governo federal: 
Gráfico 1: Quantidade de fornecedores por porte.

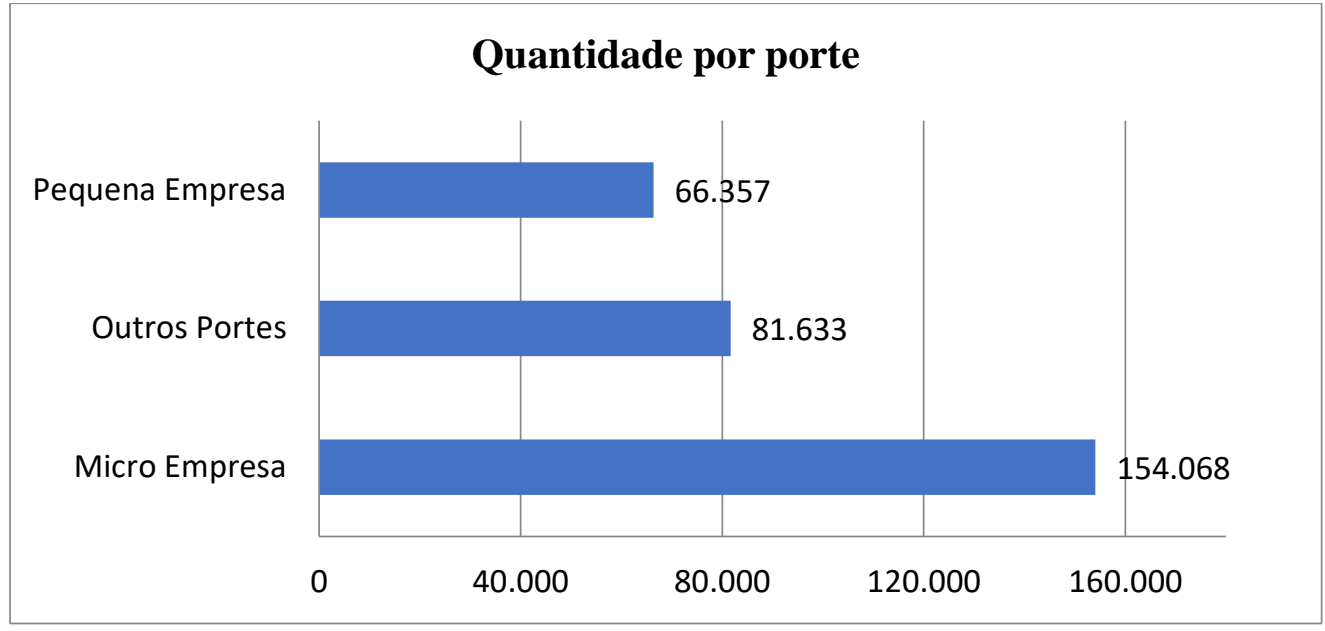

Fonte: Elaborado pelos autores, a partir do Painel de Compras/MPOG.

Comparando-se os números dos processos de compras do ano de 2012 a 2016, é possível observar que houve diminuição na evolução desses processos de compras, principalmente no período de 2014 a 2016. Isso, provavelmente, se deve ao processo político existente na época e as condições econômicas e fiscais enfrentadas pelo governo federal. O Gráfico 2 apresenta como se encontra a distribuição de processos de compras no Governo Federal: 
Gráfico 2 - Evolução do número dos processos de compras - 2012 a 2016 (em nos absolutos)

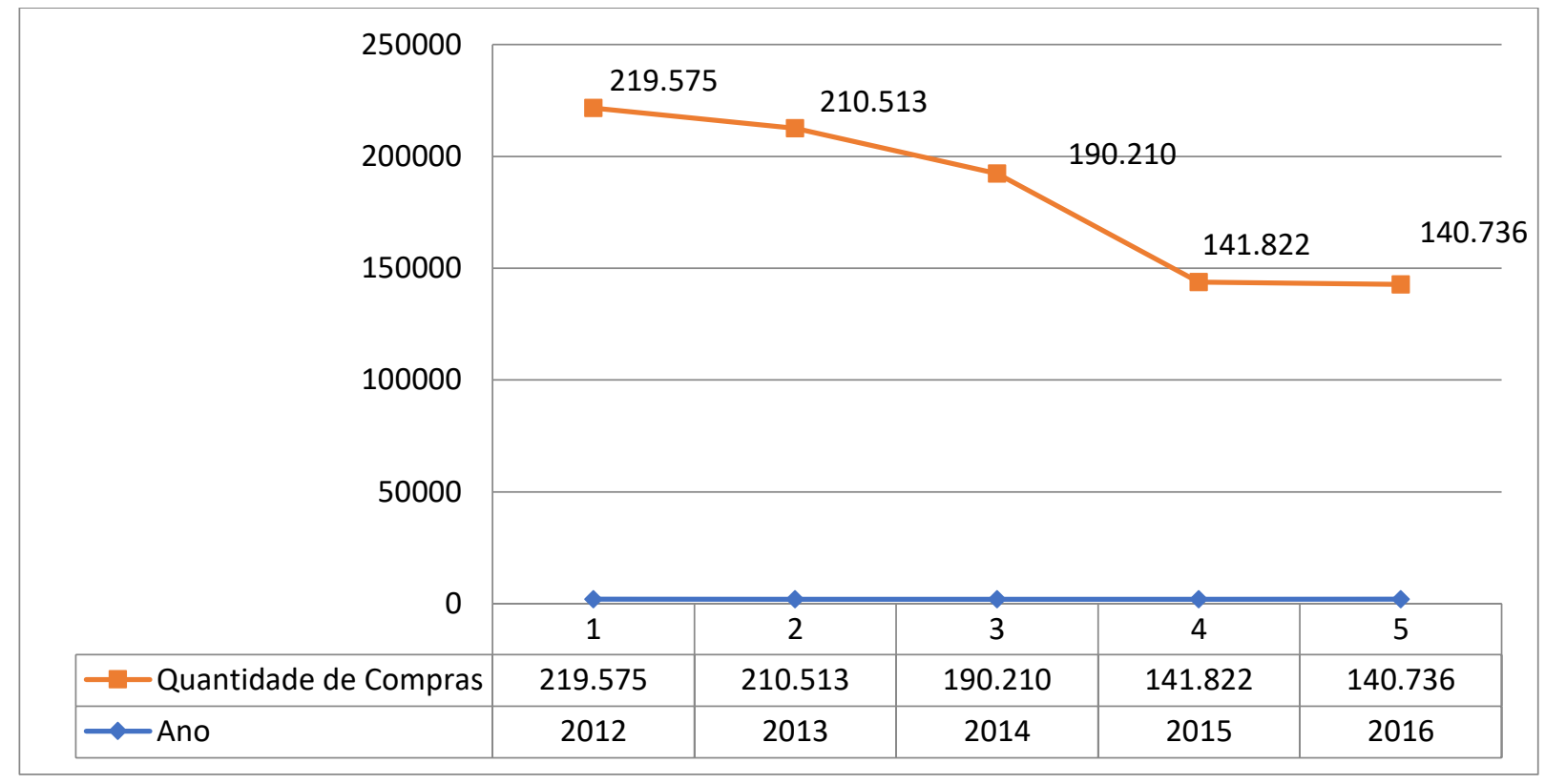

Fonte: Elaborado pelos autores, a partir do Painel de Compras/MPOG.

\subsection{Resultados obtidos no primeiro cenário - 2015 e 2016}

No período de 2015 a 2016, as compras realizadas pelo governo federal movimentaram mais $\mathrm{R} \$ 90$ bilhões de reais, porém, somente $51,86 \%$ tiveram a participação de ME/EPP. Analisando esse período, nota-se no Gráfico 3 que a somatória do valor contratado das MPEs ( $\mathrm{R} \$ 13,5$ bilhões) representa 14,30\% e, das empresas de outros portes ( $\mathrm{R} \$ 81,3$ bilhões) representam $87,70 \%$ do total das compras do governo federal: 
Gráfico 3: Valor contratado de fornecedores por porte - 2015 e 2016.

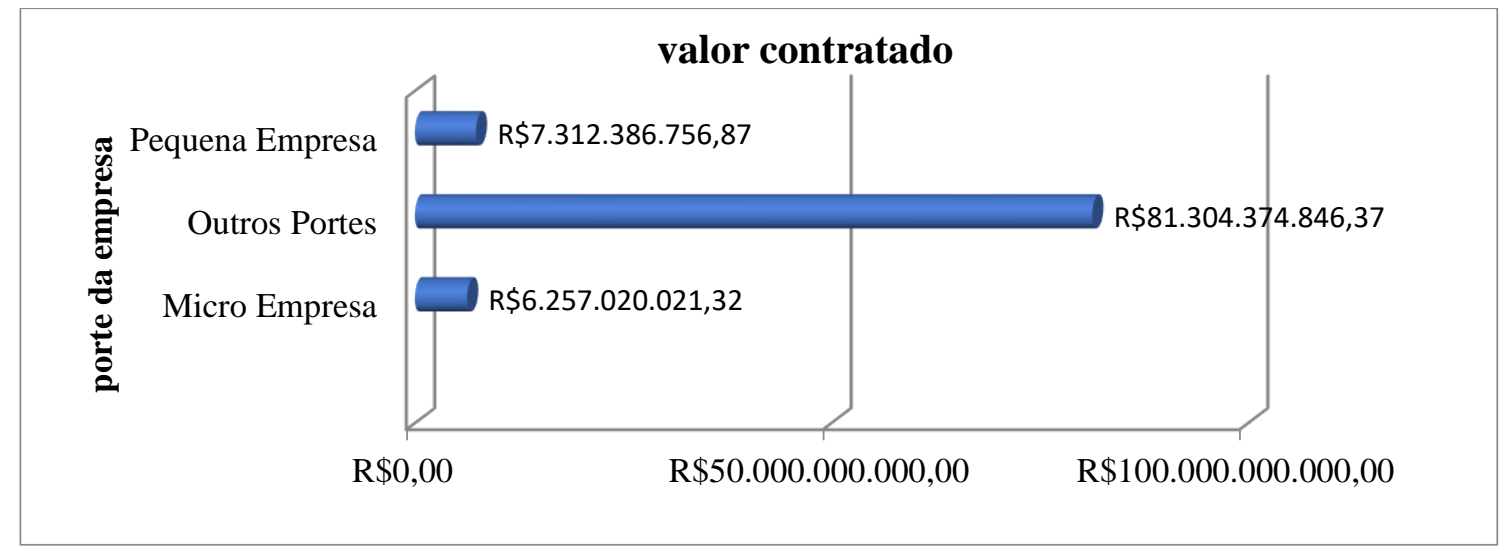

Fonte: Elaborado pelos autores, a partir do Painel de Compras/MPOG.

Analisando os dados do ano de 2015 e 2016, como demonstra a Tabela 1, a quantidade de processos de compras para as MPEs foi de 155 mil, representando 54,84\% e, das empresas de outros portes 127,6 mil e, representam $45,16 \%$ do total desses processos do governo federal. Em relação à quantidade de processos de compras apresentados na Tabela 1, há uma divergência nos valores, pois, ocorre um erro no sistema do painel de compras do governo federal, o qual não considera na somatória, em sua página inicial, os quantitativos das pequenas empresas.

Tabela 1: Quantidade de processos de compras de fornecedores por porte - 2015 e 2016.

\begin{tabular}{lcc}
\hline Porte do Fornecedor & $\begin{array}{c}\text { Quantidade de Processos de } \\
\text { Compras }\end{array}$ & Valor da Compra \\
\hline Micro Empresa & 84.776 & $\mathrm{R} \$ 6.257 .020 .021,32$ \\
Pequena Empresa & 70.175 & $\mathrm{R} \$ 7.312 .386 .756,87$ \\
Outros Portes & 127.607 & $\mathrm{R} \$ 81.304 .374 .846,37$ \\
\hline Total & $\mathbf{2 8 2 . 5 5 8}$ & $\mathbf{R} \$ \mathbf{9 4 . 8 7 3 . 7 8 1 . 6 2 4 , 5 6}$ \\
\hline
\end{tabular}

Fonte: Elaborado pelos autores, a partir do Painel de Compras/MPOG

\subsection{Resultados obtidos do segundo cenário - 2012 a 2016}

Nos últimos cinco anos, que corresponde ao período de 2012 a 2016, as compras realizadas pelo governo federal movimentaram mais de $\mathrm{R} \$ 258$ bilhões de reais. Porém, 
somente $50,85 \%$, tiveram a participação de ME/EPP e desse percentual, $22,72 \%$ das compras foram homologadas para ME/EPP.

Comparando-se o ano de 2012 a 2016, nota-se no Gráfico 4 e a Tabela 2, que a somatória do valor contratado das MPEs (R\$ 58,6 bilhões) representa 22,72\% e, das empresas de outros portes ( $\mathrm{R} \$ 199,4$ bilhões) representam 77,28\% do total das compras do governo federal.

Gráfico 4: Valor contratado de fornecedores por porte - 2012 a 2016.

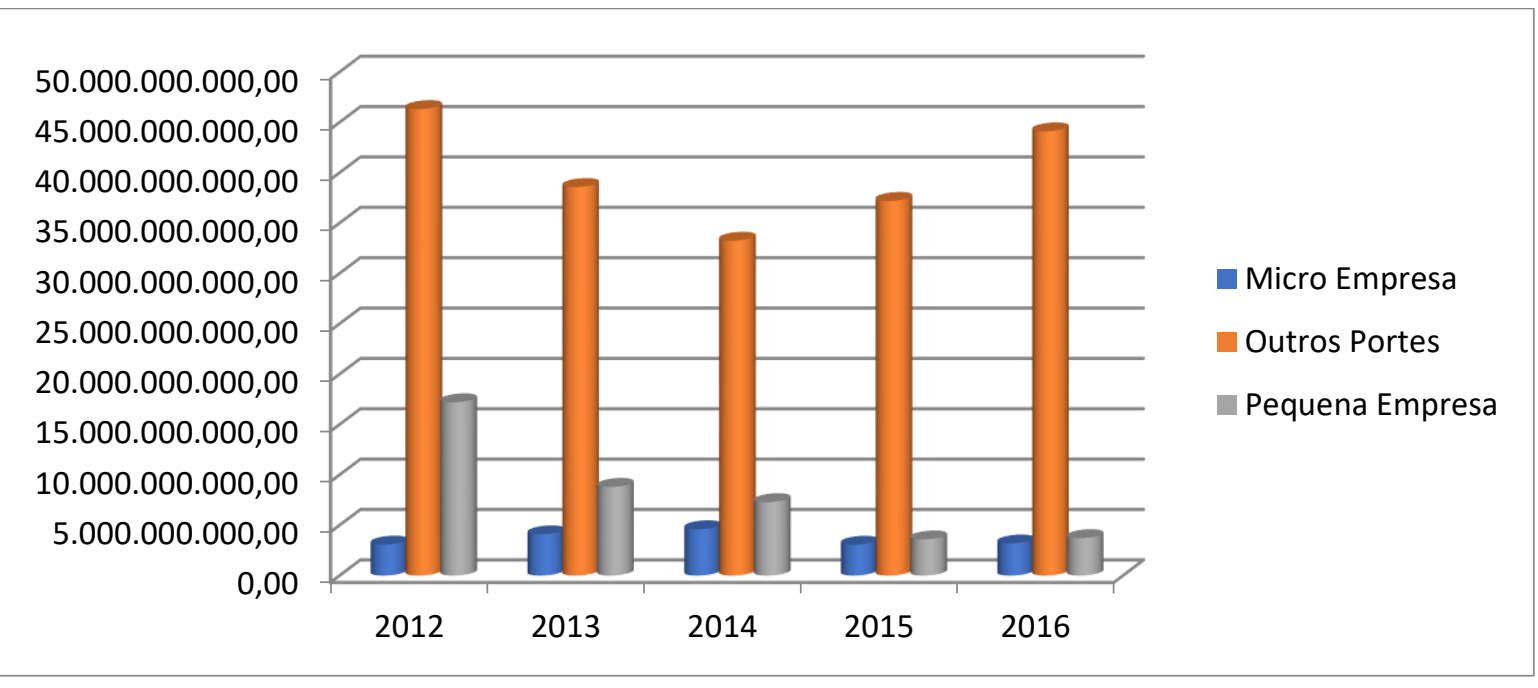

Fonte: Elaborado pelos autores, a partir do Painel de Compras/MPOG

Nesta pesquisa, foi detectado um erro no sistema do painel de compras no valor contratado de fornecedores por porte no ano de 2014. O erro identificado está relacionado ao Pregão Eletrônico n ${ }^{\circ}$ 002/2014 (SRP), do Instituto Federal de Educação, Ciência e Tecnologia do Espírito Santo - IFES - Campus Serra, pois, aparece como homologado o valor de R \$ 29.189.274.328,59 (29 bilhões), para a micro empresa vencedora, sendo que, após, pesquisas no site http://transparencia.gov.br/, o valor real da contratação no ano de 2014, para essa micro empresa do pregão eletrônico supracitado foi de $\mathrm{R} \$ 894.702,46$, o qual foi corrigido pelo autor deste estudo nos cálculos do Gráfico 4 e na Tabela 2. A divergência foi informado ao Ministério do Planejamento, Desenvolvimento e Gestão. 
Tabela 2: Valor contratado de fornecedores por porte - 2012 a 2016 (em nos absolutos).

\begin{tabular}{|c|c|c|c|c|c|c|}
\hline Porte & 2012 & 2013 & 2014 & 2015 & 2016 & TOTAL \\
\hline $\begin{array}{l}\text { Micro } \\
\text { Empresa }\end{array}$ & 3.076 .956 .534 & 4.094 .456 .540 & 4.606 .708 .977 & 3.066 .944 .516 & 3.190 .075 .505 & 18.035 .142 .073 \\
\hline $\begin{array}{l}\text { Outros } \\
\text { Portes }\end{array}$ & 46.315 .481 .756 & 38.576 .574 .800 & 33.248 .867 .547 & 37.199 .523 .635 & 44.104 .851 .210 & 199.445 .298 .950 \\
\hline $\begin{array}{l}\text { Pequena } \\
\text { Empresa }\end{array}$ & 17.205 .245 .870 & 8.807.089.836 & 7.290.183.943 & 3.594 .081 .972 & 3.718 .304 .783 & 40.614 .906 .407 \\
\hline
\end{tabular}

Fonte: Elaborado pelos autores, a partir do Painel de Compras/MPOG.

Analisando os dados do ano de 2015 e 2016, como demonstra a Tabela 3, a quantidade para as MPEs foi de 481,2 mil, representando 53,30\% e, das empresas de outros portes, 421,6 mil e representam 46,70\% do total dos processos de compras governo federal. Em relação à quantidade de processos de compras apresentados na Tabela 3, há uma divergência nos valores, pois, ocorre um erro no sistema do painel de compras do governo federal, o qual não considera na somatória em sua página inicial os quantitativos das pequenas empresas.

Tabela 3: Quantidade de processos de compras de fornecedores por porte - 2012 a 2016.

Porte do Fornecedor

\begin{tabular}{lcc}
\hline Micro Empresa & 263.486 & $18.035 .142 .073,96$ \\
Outros Portes & 421.640 & $199.445 .298 .950,84$ \\
Pequena Empresa & 217.730 & $40.614 .906 .407,82$ \\
Total & $\mathbf{9 0 2 . 8 5 6}$ & $\mathbf{2 5 8 . 0 9 5 . 3 4 7 . 4 3 2 , 6 2}$
\end{tabular}

Fonte: Elaborado pelos autores, a partir do Painel de Compras/MPOG.

Os resultados demonstraram que o tratamento favorecido, diferenciado e simplificado para as MPEs nas contratações públicas ainda tem pouco efeito, havendo um amplo mercado a ser explorado pelas pequenas empresas nas contratações do governo federal. 


\section{CONSIDERAÇÕES}

Neste artigo, foi analisada a participação das micro e pequenas empresas nas compras do governo federal, visto que exercem um relevante papel na geração de emprego, interiorização do desenvolvimento e distribuição de remuneração. Logo, são fundamentais para o desenvolvimento social no Brasil, sendo necessário uma política mais intensa, ampliando o tratamento favorecido, diferenciado e simplificado para essas empresas nas compras governamentais.

Quanto ao objetivo, os resultados do presente estudo demonstram que as normas e legislação sobre o tratamento favorecido e diferenciado para as micro e pequenas empresas, necessitam de atualizações, com o objetivo de aumentar e melhorar a participação de microempresas e empresas de pequeno porte nas compras do governo federal e consequentemente nos estados, Distrito Federal e municípios.

Embora a legislação brasileira sobre as micro e pequenas empresas tenha evoluído nos últimos anos, percebe-se nesta pesquisa a necessidade de atualizações e/ou alterações nas normas e legislações como a Lei Complementar $n^{\circ} 123 / 2006$, Lei Complementar $n^{\circ}$ 147/2014, Lei $n^{\circ} 8.666 / 93$ e Decreto $N^{\circ} 8.538 / 2015$, para aumentar e melhorar a participação de microempresas e empresas de pequeno porte nas compras do governo federal e consequentemente nos estados, Distrito Federal e municípios, podendo proporcionar inúmeros benefícios para a sociedade e para a economia brasileira.

Quanto a analisar a participação de microempresas e empresas de pequeno porte nos processos de compras do governo federal, no período de 2012 a 2016, os resultados parciais, os dados dos anos de 2012 a 2016 analisados e, como podemos observar nos Gráficos 3 e 4, que a quantidade de MPE's contratadas nas compras do governo federal em relação ao valor contratado está muito abaixo das empresas de portes maiores.

Apesar de ser um estudo quantitativo, este apresentou limitações no decorrer do processo, pois, não há na base de dados do Painel de Compras do Governo Federal, as licitações exclusivas para participação das micro e pequenas empresas.

Para futuras pesquisas, seria importante o estudo sobre participação das micro e pequenas empresas nas esferas estaduais e municipais, abrangendo um número maior de atores e maior generalização, buscando fomentar os microempresários. 


\section{REFERÊNCIAS}

BRASIL. Constituição da República Federativa do Brasil de 1988. Brasília: 1988. Disponível

em:

<http://www.planalto.gov.br/ccivil_03/constituicao/constituicaocompilado.htm>. Acesso em: 19 jan. 2018.

Lei Complementar $n^{\circ} 123$, de 14 de dezembro de 2006. Disponível em:<http://www.planalto.gov.br/ccivil_03/leis/LCP/Lcp123.htm> Acesso em: 20 jan. 2018.

Lei Complementar $n^{0}$ 147, de 7 de agosto de 2014. Disponível em: <http://www.planalto.gov.br/ccivil_03/leis/LCP/Lcp147.htm> Acesso em: 19 jan. 2018.

.Lei $\mathbf{n}^{0}$ 9.841, de 5 de outubro de 1999. Disponível em:< http://www.planalto.gov.br/ccivil_03/leis/L9841impressao.htm> Acesso em: 20 jan. 2018.

Lei $\mathbf{n}^{\mathbf{0}}$ 7.256, de 27 de novembro de 1984. Disponível em:< http://www.planalto.gov.br/ccivil_03/leis/L7256.htm> Acesso em: 20 jan. 2018.

Decreto $\mathrm{n}^{\mathrm{0}} \mathbf{8 . 5 3 8}$, de 6 de outubro de 2015. Disponível em: <http://www.planalto.gov.br/ccivil_03/_ato2015-2018/2015/decreto/d8538.htm> Acesso em: 21 jan. 2018.

.Ministério do Planejamento, Orçamento e Gestão. Comprasnet. Disponível em: $<$ https://www.comprasgovernamentais.gov.br/images/conteudo/ArquivosCGNOR/compr as-publicas-29out2014.pdf> Acesso em: 22 fev. 2018.

Disponível

.Ministério do Planejamento, Orçamento e Gestão. Painel de Compras. em:https://paineldecompras.planejamento.gov.br/QvAJAXZfc/opendoc.htm?document= PaineldeCompras.qvw\&host=QVS@17-0112-b-ias04\&anonymous=true> Acesso em: 21 jan. 2018.

.Ministério do Planejamento, Orçamento e Gestão. Disponível em.<http://www.planejamento.gov.br/> Acesso em: 15 fev. 2018.

CABRAL, Sandro; REIS, Paulo Ricardo da Costa; SAMPAIO, Adilson da Hora. Determinantes da participação e sucesso das micro e pequenas empresas em compras públicas: uma análise empírica. Rev. Adm. (São Paulo), São Paulo, v. 50, n. 4, p. 477 491, Dec. 2015 Available from $<$ http://www.scielo.br/scielo.php?script=sci_arttext\&pid=S0080-

$21072015000400477 \& \operatorname{lng}=$ en\&nrm=iso $>$. access on 03 Feb. 2018. http://dx.doi.org/10.5700/rausp1214. 
DI PIETRO, Maria Sylvia Zanella Di Pietro. Direito Administrativo. 26ª ed. São Paulo, Editora Atlas S.A., 2013.

GIL, A. C. Métodos e técnicas de pesquisa social. 5.ed. São Paulo: Atlas, 1999.

JUSTEN FILHO, Marçal. Comentários à Lei de Licitações e Contratos Administrativos. 12. ed. São Paulo: Dialética, 2008.

JUSTEN FILHO, Marçal. Pregão: comentários à legislação do pregão comum e eletrônico. 5 ed.. São Paulo: Dialética, 2009.

MINAYO, M. C. de S. Trabalho de campo: contexto de observação, interação e descoberta In. MINAYO, M. C. de S.; DESLANDES, S. F. GOMES, R. (Org). Pesquisa social: teoria, método e criatividade. $28^{\text {a }}$. ed. Petrópolis: Vozes, 2009.

SAMPAIO, Adilson da Hora. Um estudo sobre a participação das micro e pequenas empresas nos pregões eletrônicos realizados na FIOCRUZ/BA. 2012. 77f. Dissertação (mestrado profissional) - Universidade Federal da Bahia, Escola de Administração, Salvador, $2012 . \quad$ Disponível em: <http://www.adm.ufba.br/sites/default/files/publicacao/arquivo/adilson_da_hora_sampa io.pdf>. Acesso em: 02 jan. 2018.

SEBRAE. Participação das Micro e Pequenas Empresas na Economia Brasileira. Disponível em:<http://www.biblioteca.sebrae.com.br/bds/bds.nsf/8F5BDE79736CB994832574470 06CBAD3/\$File/NT00037936.pdf> Acesso em: 15 de mar 2018.

SEBRAE. As principais mudanças da lei geral das micro e pequenas empresas. Disponível em: <https://www.sebrae.com.br/Sebrae/Portal\%20Sebrae/UFs/ES/Artigos/CARTILHA. pdf $>$ Acesso em: 09 de mar 2018. 